\title{
Aneurysmal Rupture Without Subarachnoid Hemorrhage: A Case Report Abstract
}

\author{
Catherine Harris, PhD, CRNP \\ Thomas Jefferson University \\ Amrith Jamoona, MD \\ Thomas Jefferson University \\ Ciro Randazzo MD, MPH \\ Thomas Jefferson University
}

Follow this and additional works at: https://jdc.jefferson.edu/jhnj

\section{Let us know how access to this document benefits you}

\section{Recommended Citation}

Harris, PhD, CRNP, Catherine; Jamoona, MD, Amrith; and Randazzo, Ciro MD, MPH (2013) "Aneurysmal Rupture Without Subarachnoid Hemorrhage: A Case Report Abstract," JHN Journal: Vol. 8 : Iss. 1 , Article 6.

DOI: https://doi.org/10.29046/JHNJ.008.1.006

Available at: https://jdc.jefferson.edu/jhnj/vol8/iss1/6

This Article is brought to you for free and open access by the Jefferson Digital Commons. The Jefferson Digital Commons is a service of Thomas Jefferson University's Center for Teaching and Learning (CTL). The Commons is a showcase for Jefferson books and journals, peer-reviewed scholarly publications, unique historical collections from the University archives, and teaching tools. The Jefferson Digital Commons allows researchers and interested readers anywhere in the world to learn about and keep up to date with Jefferson scholarship. This article has been accepted for inclusion in JHN Journal by an authorized administrator of the Jefferson Digital Commons. For more information, please contact: JeffersonDigitalCommons@jefferson.edu. 


\section{Aneurysmal Rupture Without Subarachnoid Hemorrhage: A Case Report Abstract}

Catherine Harris PhD, CRNP; Amrith Jamoona, MD; Ciro G. Randazzo, MD, MPH

Department of Neurosurgery, Thomas Jefferson University and Jefferson Hospital for Neuroscience, Philadelphia, Pennsylvania, USA

\begin{abstract}
Introduction: The present case study reports an intraparenchymal hemorrhage from a ruptured basilar tip aneurysm without subarachnoid hemorrhage.

Case Report: A 57-year-old male presented with intraparenchymal hemorrhage from a ruptured basilar tip aneurysm without subarachnoid hemorrhage. The patient had successful endovascular embolization of his ruptured cerebral aneurysm 9 years previously.

Discussion: Ruptured cerebral aneurysms without subarachnoid hemorrhage are extremely rare. Cerebral angiogram for atypical presentation of patients with intracranial hemorrhages should be considered. In patients with known cerebral aneurysms who present with an intracranial hemorrhage, rupture of that aneurysm or a de novo aneurysm must be ruled out.
\end{abstract}

\section{INTRODUCTION}

Intracranial aneurysmal rupture most often presents with subarachnoid hemorrhage but may also present with intraparenchymal hemorrhage(IPH), intraventricular hemorrhages (IVH) and subdural hematomas (SDH) ${ }^{1-4}$ The incidence of SAH with IPH, IVH and SDH is $40 \%, 17 \%$ and $35 \%$, respectively. ${ }^{5-7}$ However, the presence of a ruptured aneurysm presenting as IPH, IVH or SDH without SAH is extremely rare. ${ }^{8-13}$ The purpose of this case study is to report a patient with IPH from a ruptured aneurysm without subarachnoid hemorrhage.

\section{CASE PRESENTATION}

The patient is a 57-year-old white male who experienced an initial Hunt and Hess Grade III subarachnoid hemorrhage 9 years earlier and was treated at an outside hospital. At that time, he underwent endovascular treatment of a $10 \mathrm{~mm}$ basilar tip aneurysm. He required ventriculoperitoneal shunt placement for persistent hydrocephalus. Two years later, he was found to have a recurrence and underwent repeat coiling. At 6 months follow-up, he had almost 100\% occlusion of the aneurysm with only a small wide neck remnant. No further recanalization had been seen one year later. The patient did not return for further follow up until he presented to the office five years later with complaints of headaches, double vision and right eye pain. His headaches had been occurring daily although not unusual for him, as he suffered from sinus problems in the past. However, he had a CT of the sinuses done two weeks prior to his office visit, which did not show any evidence of sinusitis.

His past medical history was significant for subarachnoid hemorrhage, hypertension, hyperlipidemia, benign prostatic hypertrophy and erectile dysfunction. His only surgery was the placement of the shunt. His medications included a baby aspirin, clopidogrel, atorvastatin and an antihypertensive medication. He had allergies to percocet and percodan. The patient quit smoking at the time of his subarachnoid hemorrhage and did not resume his habit. He denied use of alcohol. He remained married, but unemployed. He had no family history of any type of aneurysms or intracranial hemorrhages. Aside from his presenting complaints his review of systems was negative. On physical examination his only significant finding was left pupil anisocoria. The patient was told to obtain a CT of the head as soon as possible as well as MRI/MRA of the head and neck to rule out recurrence of his aneurysm. The patient obtained his CT head after leaving the office and was found to have a small left thalamic hemorrhage without evidence of subarachnoid hemorrhage. He was admitted to the hospital.

\section{DISCUSSION}

Intracranial hemorrhages including IPH and IVH are known to occur in conjunction with $\mathrm{SAH}$ after the rupture of a cerebral aneurysm. There is a close correlation between the site of the hematoma and the location of the aneurysm. Mycotic aneurysms and neoplastic aneurysms have been reported as presenting with IPH, but typically have cortical SAH. ${ }^{12,14-15}$ The morphology of mycotic and neoplastic aneurysms tends to be different from typical saccular aneurysms as they tend to form on smaller vessels deeper within the brain tissue. Although infrequent, SDH can also occur after an aneurysm rupture presumably from the rupture of a cortical aneurysm or an aneurysm extending into the arachnoid space. ${ }^{16-19}$ Cerebral aneurysms that cause an intracranial hemorrhage without SAH are extremely rare with only a few case studies being reported. Bismar ${ }^{5}$ (1994), found in their sample that only $1.9 \%$ of ruptured aneurysms presented without SAH. Similarly Thai et al. ${ }^{13}$ found the incidence to be $1.1 \%$. The case reports which presented cases of aneurysmal ruptures without SAH included IPH from a distal left posterior cerebral artery mycotic and saccular aneurysms ${ }^{20}$; IPH and SDH from an anterior ethmoidal artery aneurysm 2 ; and SDH from a middle meningeal artery aneurysm. ${ }^{3}$ Thai et al., looking at 13 patients ${ }^{13}$, did a case series on aneurysmal rupture without $\mathrm{SAH}$. Eleven patients presented with temporal IPH, one had isolated IVH from a basilar apex aneurysm rupture and one patient had a superior dorsal thalamic IPH. They concluded that patients with an IPH in the temporal lobe or isolated IVH should be considered as criteria for an urgent workup of a ruptured aneurysm regardless of the presence of SAH. 
Hypertension is the most common cause of an isolated IPH, however Halpin et al. found structural lesions in $74 \%$ of patients under the age of $50 .{ }^{21}$ In patients under the age of 50 who were known to be normotensive with an isolated IPH, $83 \%$ had an underlying structural lesion. ${ }^{22}$ When a patient presents with an isolated IPH without SAH, ruptured aneurysm should remain in the differential diagnosis and be considered.

In this case report, the patient had a previous rupture of a basilar tip aneurysm with extensive SAH necessitating a ventriculoperitoneal shunt. Approximately 9 years later, the same aneurysm reruptured but causing only IPH without SAH. The possibility remains that the SAH spontaneously resolved prior to obtaining CT head or was undetectable. Regardless, the initial CT head showed a thalamic hemorrhage as a presenting symptom that could have easily been treated as an isolated hypertensive IPH. Knowing the patient had a history of a basilar aneurysm made his condition suspicious for a ruptured cerebral aneurysm.

\section{CONCLUSION}

We report a case of recurrent rupture of a basilar tip aneurysm with IPH but no subarachnoid hemorrhage that occurred 9 years after the initial injury. Recurrent subarachnoid hemorrhage after successful embolization of a cerebral aneurysm is rare. Recurrent rupture of the aneurysm without SAH is extremely rare with only a few cases reported. Patients presenting with IPH, IVH or SDH with a known aneurysm should be admitted for an urgent workup for possible rupture. In addition, patients with atypical presentations associated with IPH, IVH or SDH without SAH should also be considered for cerebral angiograms to rule the possibility of an underlying structural lesion such as a ruptured aneurysm.

\section{REFERENCES}

1. Ragland RL, Gelber ND, Wilkinson HA, Knorr JR, Tran AA. Anterior communicating artery aneurysm rupture: an unusual cause of acute subdural hemorrhage. Surg Neurol. 1993; 40: 400-402.

2. Ranjan A, Joseph T. Giant aneurysm of anterior ethmoidal artery presenting with intracranial hemorrhage: case report. J Neurosurg. 1994; 81:934-936.

3. Sandin JH, Salamat MS, Baskaya M, Dempsey RJ. Intracerebral hemorrhage caused by the rupture of a nontraumatic middle meningeal artery aneurysm: case report and review of the literature. J Neurosurg. 1999; 90: 951-954

4. Biesbroek JM, Rinkel GJE, Algra A, van der Sprenkel JWB. Risk factors for acute subdural hematoma from intracranial aneurysm rupture. Neurosurgery. 2012; 71: 264-269.

5. Bismar J. Computer tomography as the primary radiologic procedure in acute subarachnoid hemorrhage. Acta Radiol Diagn. 1979; 20: 849-864.

6. Masson RL, Day AL. Aneurysmal intracerebral hemorrhage. Neurosurg Clin N Am. 1992; 3: 539-550.

7. Pasqualin A, Bazzan A, Cavazzani P, Scienza R, Licata C, Da Pian R. Intracranial hematomas following aneurysmal rupture: experience with 309 cases. Surg Neurol. 1986; 25: 6-17.

8. Ishibashi A, Yokokura Y, Sakamoto M. Acute subdural hematoma without subarachnoid hemorrhage due to ruptured intracranial aneurysm: case report. Neurol Med Chir (Tokyo). 1997; 37: 533-537.

9. Yanaka K, Shirai S, Kimura H, Nose T. Concurrent subarachnoid hemorrhage due to ruptured aneurysm and hypertensive intracerebral hemorrhage: a case report. Neurol Med Chir (Tokyo). 1994; 34: 304-306.

10. Sugita Y, Yoneda S, Watanabe T, Shigemori M. Simultaneous occurrence of aneurysmal subarachnoid hemorrhage and remote intracerebral hemorrhage: case report. Neurol Med Chir (Tokyo). 1995; 35: 591-593.

11. Crum BA, Wijdicks EFM. Thalamic hematoma from a ruptured posterior cerebral artery aneurysm. Cerebrovascular Diseases. 2000; 10: 475-477.

12. Regelsberger J, Elsayed A, Matschke J, Lindop G, Grzyska U, van den Boom L, Venne D. Diagnostic and therapeutic considerations for "mycotic" cerebral aneurysms - 2 case reports and review of the literature. Central European Neurosurgery. 2011; 72: 138-143.
13. Thai QA, Raza SM, Pradilla G, Tamargo RJ Aneurysmal rupture without subarachnoid hemorrhage: case series and literature review. Neurosurgery. 2005; 57: 225-229.

14. Murata J, Sawamura Y, Takahashi A, Abe H, Saitoh $H$. Intracerebral hemorrhage caused by a neoplastic aneurysm from small-cell lung carcinoma: case report. Neurosurgery. 1993; 32:124-126.

15. Kadota Y, Hatashita S, Sakakibara T, Takagi S. Intracerebral hemorrhage from a peripheral aneurysm associated with an astrocytoma: case report. Neurol med Chir (Tokyo). 1989; 29: 241-244.

16. Nishikawa T, Ueba T, Kajiwara M, Yamashita K. Bilateral acute subdural hematomas with intracerebral hemorrhage without subarachnoid hemorrhage, caused by rupture of an internal carotid artery dorsal wall aneurysm: case report. Neurol Med Chir (Tokyo). 2009; 49: 152-154.

17. Marbacher S, Fandino J, Lukes A. Acute subdural hematoma from ruptured cerebral aneurysm. Acta Neurochir. 2010; 152: 501-507.

18. Kamiya K, Inagawa T, Yamamoto M, Monden S. Subdural hematoma due to ruptured intracranial aneurysm. Neurol Med Chir (Tokyo). 1991. 31: 82-86.

19. Weir B, Myles T, Kahn M, Maroun F, Malloy D, Benoit B et al. Management of acute subdural hematomas from aneurysmal rupture. Can J Neurol Sci. 1984; 11: 371-376.

20. Barami K, Ko K. Ruptured mycotic aneurysm presenting as an intraparenchymal hemorrhage and nonadjacent acute subdural hematoma: case report and review of the literature. Surg Neurol. 1994: 41: 290-293.

21. Halpin SF, Britton JA, Byrne JV, Clifton A, Hart G, Moore A. Prospective evaluation of cerebral angiography and computed tomography in cerebral haematoma. J Neurol Neurosurg Psychiatry. 1994; 57: 1180-1186.

22. Inci S, Akbay A, Hazer B, Yavuz K, Ozgen T. Ruptured aneurysm at the perforating artery supplying the insula: case report. Neurosurgery. 2009; 65: E206-E207. 